\title{
Acetonitrile: A Plausible Source of Amino Acids on the Primitive Earth.
}

\author{
${ }^{1}$ Kavita Gururani, ${ }^{2}$ Chandra Kala Pant, ${ }^{3} \mathrm{H}$.D .Pathak . \\ ${ }^{1,2,3}$ Chemical laboratory, Department of Chemistry, D.S B. Campus, Kumaun University, Nainital.
}

\begin{abstract}
Synthesis of amino acids from aqueous solution of acetonitrile has been carried out by the action of heat.and revealed the formation of lysine, aspartic acid, serine, glycine, glutamic acid, alanine, valine and leucine. Amino acid synthesis was accelerated in the presence of copper exchanged montmorillonite clay followed by calcium and magnesium exchanged clays. Synthesis of important biomolecules from aqueous solution of acetonitrile may throw some light on the process of chemical evolution.
\end{abstract}

Keywords: Absorption, Chromatographic, Montmorillonite, Prebiotic, Sensitisers.

\section{Introduction}

The earth was formed some 4-5 million years ago. ${ }^{1-4}$ Atmospheric components like $\mathrm{H}_{2}, \mathrm{NH}_{3}, \mathrm{H}_{2} \mathrm{O}$ and $\mathrm{CH}_{4}$ are believed to have been formed under the action of UV light, lightening, shock waves, heat and other forms of energy ${ }^{5-8}$. Among these compounds are the primordial biomolecules like amino acids, purine, pyrimidines, sugars (pentoses and hexoses) etc. These compounds or their precursors have been detected in fossils, meteorites and in the interstellar space. Hydrogen cyanide is considered to be a major precursor of nitrogenous organic molecules leading to the formation of cyanamide, cyanoacetylene and nitriles ${ }^{9-10}$.

Abiotic synthesis precursors of specific life forming molecules has been investigated by earlier workers ${ }^{11-13}$. Hydrogen cyanide ,acetonitrile, cyanoacetylene and amino nitriles have been reported as reactive intermediates during discharge experiments ${ }^{14-16}$. Formation of acetonitrile by photolysis of acetylene and ammonia has been reported by Ferris and Ishikava ${ }^{17}$. Most common reaction pathways leading to the abiotic formation of simple organic compounds containing $\mathrm{N}_{2}$ is hydrogen cyanide, which is readily formed by reactions such as :

$2 \mathrm{CH}_{4}+\mathrm{N}_{2} \rightarrow 2 \mathrm{HCN}+3 \mathrm{H}_{2}$

$\mathrm{CO}+\mathrm{NH}_{3} \rightarrow \mathrm{HCN}+\mathrm{H}_{2} \mathrm{O}$

These reactions are promoted by heat ,UV light or electric discharges.Under simulated primitive earth conditions $\mathrm{HCN}$ is in turn is a precursor of other highly reactive compounds as cyanoacetylene, cyanamide, and nitriles which in turn are precursors of a variety of amino acids,purines and pyrimidines.UV initiated formation of amino acids has beeen reported from aqueous solution of hydrogen cyanide,acetonitrile and acryonitrile by Ferris et.al ${ }^{18 .}$ and Pathak .et.al ${ }^{19}$. However ,heat induced synthesis of amino acids from aqueous solution of acetonitrile in presence and absence of montmorillonite clay with or without divalent cations has not been studied in detail. Therefore attempts have been made to synthesise biologically significant molecules from reaction system of acetonitrile -water vapor under conditions believed to have existed near hydrosphere lithosphere boundaries of the primitive sea.

\section{II.}

Experimental Procedure

\subsection{PREPARATION OF SOLUTION:}

All the investigations were carried out in aqueous medium. Sterilized double distilled water was used as the solvent in every experiment wherever necessary the vapors of the double distilled water was allowed to pass through the reaction vessels. Every care was taken to ensure the purity of the samples employed. .

Experimental solution $(5 \mathrm{ml}$ each) with $\mathrm{pH} 9.0 \pm 0.5$ were heated in borosil glass reaction vessels- Kjeldhal flasks $(100 \mathrm{ml})$ fitted with air condensers on hot plates at a temperature of $90 \pm 5^{\circ} \mathrm{C}$ in the presence and absence of montmorillonite clay with or without divalent cations $\left(\mathrm{Mg}^{2}+, \mathrm{Cu}^{2}+, \mathrm{Ca}^{2}+\right)$.

Samples of reaction concentrates were analyzed for the possible formation of amino acids using chromatographic techniques on Whatman No- 01 paper both by uni- and two dimensional chromatography using butanol- acetic acid- water (4:1:1 v/v, 4:1:5 v/v upper layer), butanol- acetic acid- pyridine- water $(15: 3: 10: 12 \mathrm{v} / \mathrm{v})$ and phenol- water $(80: 20 \mathrm{v} / \mathrm{v})$. Amino acid spots were visualized with ninlydrin, identified with isatin and also by comparison of their Rf values with authentic amino acids as well as of their DNP derivatives. For the separation of DNP amino acids the solvent system used was n- butanol saturated with water. Colorimetric estimation of amino acids was carried out by comparison of color intensity of the unknown compound with that of a standard solution employing photochemical colorimeter MK 
Acetonitrile: A Plausible Source Of Amino Acids On The Primitive Earth.

\section{2:ULTRAVIOLET SPECTRA:}

Ultraviolet absorption spectra of the various reaction mixtures or elutes of some products were determined in aqueous solution using Jasco V- series spectrophotometer.

\section{3:INFRA RED SPECTROSCOPY:}

IR spectra of reaction concentrates were recorded in Perkin Elmer $881\left(4000-6000 \mathrm{~cm}^{-1}\right)$ spectrophotometer.

\subsection{HIGH PERFORMANCE LIQUID CHROMATOGRAPHY:}

The reaction products were further identified by High Performance Liquid Chromatography which were ascertained by SHIMADZU SPD- 10 A UV visible detector with $\mathrm{C}_{18}$ column using triple distilled water: methanol $(80: 20 \mathrm{v} / \mathrm{v})$ and $0.1 \% \mathrm{H}_{3} \mathrm{PO}_{4}$ : acetonitrile $(40: 60 \mathrm{v} / \mathrm{v})$ as mobile phase, flow rate $1.5 \mathrm{ml} / \mathrm{min}$ at $\mathrm{pH} 7.0$, temperature $25^{\circ} \mathrm{C}$ and UV detector monitored at $197-210 \mathrm{~nm}$ for the detection of amino acids. Results were compared with retention times of the standard amino acids run in the same HPLC column under similar conditions.

In every experiment an identical solution heavily wrapped in several folds of black cloth and paper was kept along side of the reaction vessels in small pyrex flasks without heating. Such solutions were tested and analyzed in the same way as that of the experimental solutions.

Portions of heated samples were taken out with the help of sterilized measuring cylinders of different measurments. For the chromatographic analysis, the heated samples were concentrated in vacuum evaporator.The concentrates of experimental samples were analysed by paper chromatography on Whatman No. 1 filter paper chromatographically and also by chemical methods.

\section{SOLVENT SYSTEM :}

The solvent systems used for the development of papergram were prepared by employing high grade extra pure chemicals supplied by BDH/ E. Merck, Qualigens, exclusively meant for the chromatographic investigations of biologically significant molecules. The solvent is selected in such a way that the resolution of samples components is satisfactory.

Solvent system used in analyzing amino acids were:

i. $\quad \mathrm{n}$ - butanol-acetic acid-water [4:1:1 v/v]

ii. n-butanol-acetic acid-water [4:1:5 v/v upper layer]

\section{Results :}

Formation of amino acids from reaction system of acetonitrile-water vapor have been carried out in presence and absence of Montmorillonite clay with or without divalent cations under the effect thermal energy simulating conditions believed to have existed near hydrosphere-lithosphere boundaries of the primitive sea. The presence of large amounts of solid surfaces such as ,clay minerals, metal ferrocyanides and metal oxides on the prebiotic earth crust have been reported. The possibility that weather these solid surface play a role in the origin and early evolution of the life on earth? This possibility has received considerable attention in the past few decades.

The effect of heat on reaction system comprised of acetonitrile and water vapour in presence and absence of montmorillonite clay with or without cations has been investigated for the possible formation of amino acids in round bottom flasks kept on hot plates at $90 \pm 5{ }^{\circ} \mathrm{C}$ under wetting and drying conditions. The $\mathrm{pH}$ was maintained at $8.5 \pm 0.5$.

Heating was continued till the last drop of reaction concentrate was left. After completion of each cycle fresh double distilled water was added to the flask for the next cycle to start. Heated concentrate of acetonitrile and water vapour drawn out periodically after $10 \mathrm{hrs}, 25 \mathrm{hrs}, 50 \mathrm{hrs}$, and $100 \mathrm{hrs}$ were subsequently analyzed by paper chromatography and HPLC for the formation of amino acids. The resulting products were further characterized by various physico-chemical methods and UV/IR spectral studies.

Paper chromatographic analysis of reaction concentrate heated for short period up to $10 \mathrm{hrs}$ showed no ninhydrin positive spots on the papergram .Prolonging the duration of heating for 25 hrs showed four chromatographically separable ninhydrin positive products glycine(II) and leucine(IX) were formed in appreciable amount. (fig.1a).Heating the reaction system up to $50 \mathrm{hrs}$ enhanced the amount of all these products along with the formation of three new products (fig. $1 \mathrm{~b}$ ). On extending the heating period up to $75 \mathrm{hrs}$, in all nine products appeared on the papergram. Lysine was formed in moderate amount while other products in good amount(fig $1 \mathrm{c})$. On further prolonging the duration of heating for $100 \mathrm{hrs}$ almost identical range of products were formed. Glycine(II)was formed in good amount while products lysine, glutamic acid, $\alpha$-alanine valine and leucine were formed in moderate amount Fig (1d ).However, identity of products V,VIand VIII could not be ascertained Fig (1d ). 
The quantitative estimation and physico -chemical properties of the resulting thermal products have been recorded in table 01 and shown in figure01.

Thus ,time lapse studies have shown that formation of amino acids depends upon the duration of heating.

The UV-absorption spectra of the reaction concentrate heated for $100 \mathrm{hrs}$. showed a band at $203 \mathrm{~nm}$. The band corresponding to $203 \mathrm{~nm}$ consist of amino acids because their absorption band lies in this region 193-220nm(Fig $02)$.

The results were further confirmed by high performance liquid chromatography. $10 \mu 1$ sample of reaction concentrate of acetonitrile and water vapour heated up to $100 \mathrm{hrs}$ was injected in SHIMADZU SPD 10A UV -visible detector with $\mathrm{C} 18$ column monitored at $210 \mathrm{~nm}$, mobile phase $1 \% \mathrm{H}_{3} \mathrm{PO}_{4}(\mathrm{pH} 2.8)$, temperature $24^{\circ} \mathrm{C}$, flow rate $1.0 \mathrm{ml} / \mathrm{min}$ showed peaks corresponding to glutamic acid $(3.840 \mathrm{~min}$.), glycine (4.023 min), $\alpha$-alanine (4.421 min.),valine (5.088 min.),leucine (56.965min.) and lysine (10.001 min.) matched with standard amino acids run under identical conditions.(Fig 03)

Heating the reaction system of acetonitrile and water vapour with montmorillonite clay with or without divalent cations $\left(\mathrm{Ca}^{2+} \mathrm{Cu}^{2+} \mathrm{Mg}^{2+}\right.$ for a period of $100 \mathrm{hrs}$ under wetting and drying condition and on subsequent chromatographic analysis showed the formation of eight ninhydrin positive products on the papergram.Out of these ,products lysine, aspartic acid and leucine were formed in trace amount whereas serine, glycine, $\alpha$-alanine and valine in moderate amount.(Fig. 4a)

Results are recorded in table 2 and illustrated in Fig04.

In presence of $\mathrm{Cu}^{2+}$ exchanged montmorillonite clay serine, glycine,,$\alpha$-alanine and valine were formed in appreciable amount while other products in lesser amount.(Fig.4b)

The effect of heat on same reaction system in presence of $\mathrm{Ca}^{2+}$ clay showed eight products on the papergram.( Fig.4c)

In presence of $\mathrm{Mg}^{2+}$ exchanged clay identical range of amino acids were formed.Serine, glycine and valine were formed in appreciable amount as compared to other products..(Fig. 4d)

On the basis of quantitative analysis of amino acids formed from reaction system of acetylene -ammonia and water vapour under prebiotic wetting -drying thermal conditions was found in the following order -

Where, $\mathrm{M}=$ montmorillonite clay.

$$
\mathrm{M} . \mathrm{Cu}^{2+}>\mathrm{M} \cdot \mathrm{Ca}^{2+}>\mathrm{M}^{2} \mathrm{Mg}^{2+}>\mathrm{M}
$$

\section{Conclusion:}

From the results discussed above, it may be concluded that acetonitrile formed by photolysis of acetylene and ammonia gases in the atmosphere, might have transported to the earths surface alongwith rain water as the primitive earth cooled and would have contributed in the formation of amino acids by the action of heat energy. The clay minerals available near sea-shores might have catalysed the formation of biomonomers by the process of adsorption and desorption and also stabilized them from decomposition via electrostatic forces of attraction .

\section{TABLE- 01}

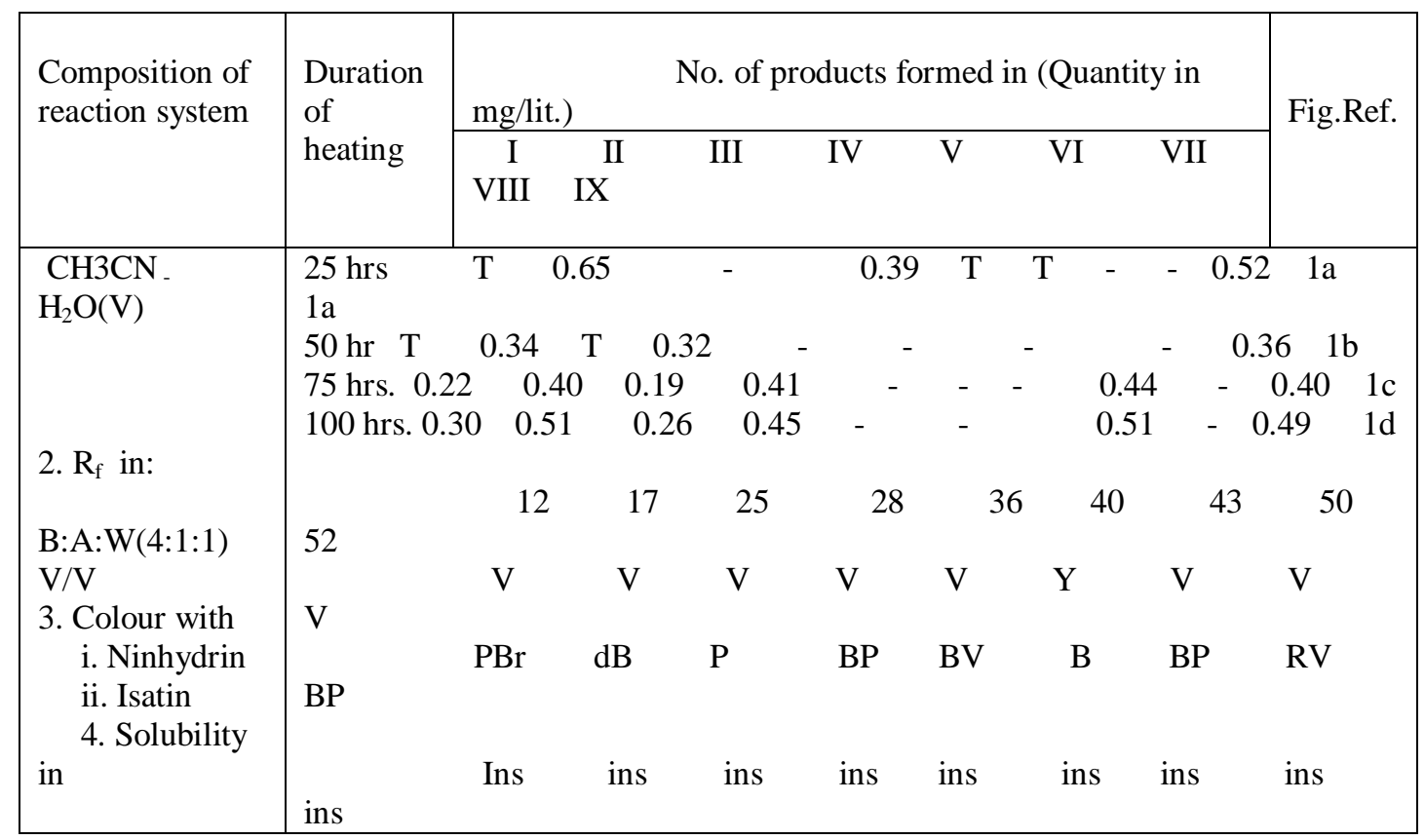


Acetonitrile: A Plausible Source Of Amino Acids On The Primitive Earth.

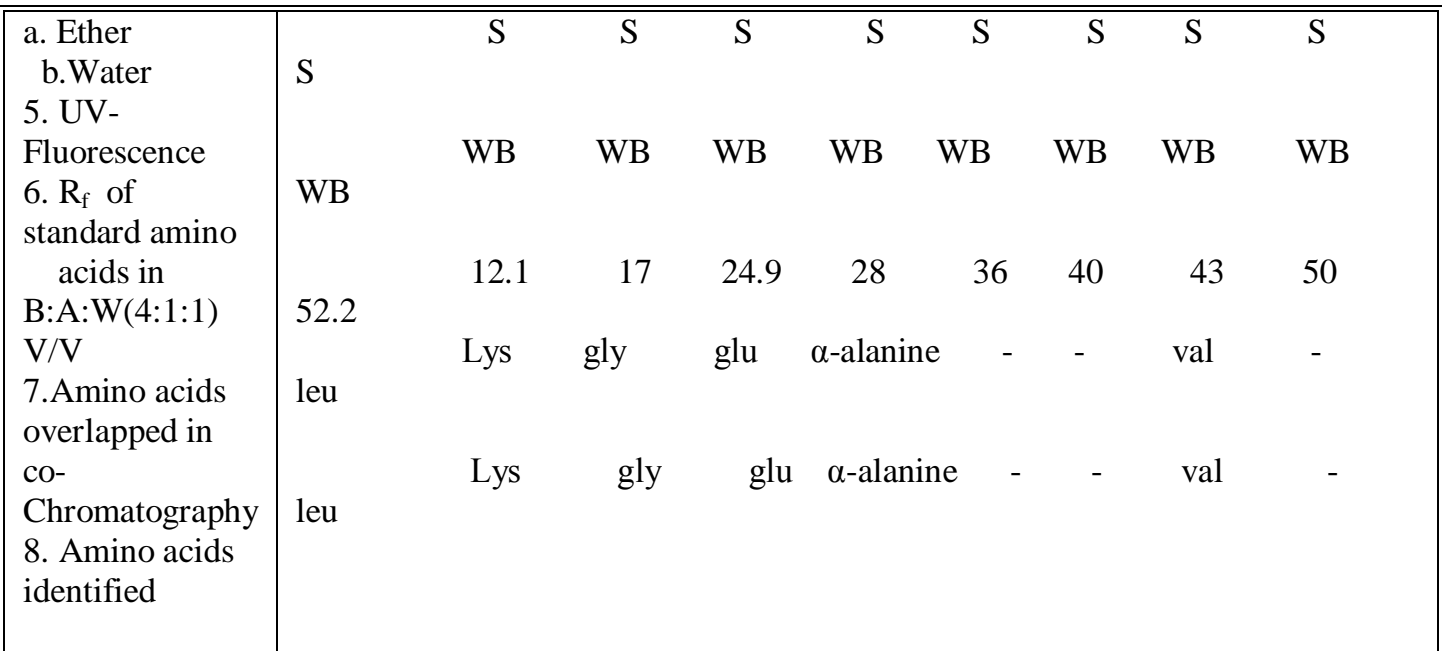

Heat induced $\left(90 \pm 5^{0} \mathrm{C}\right)$ synthesis of amino acids from reaction system of acetonitrile -water vapor under primitive earth conditions.

n-BAW, n-butanol: acetic acid: water 4:1:1 V/V;V- violet; RV-Reddish Violet; Violet; PBr-Pink brown; dB-Dull blue; P-Pink; BV-Blue violet; B-Blue; BP-Blue pink; RV-Red violet; ins- insoluble; s- soluble; lys- lysine; gly-glycine; $\alpha$-ala- $\alpha$-alanine; $\mathrm{R}$ val- valine; leu- leucine.Rf values were calculated at $250 \mathrm{C}$.

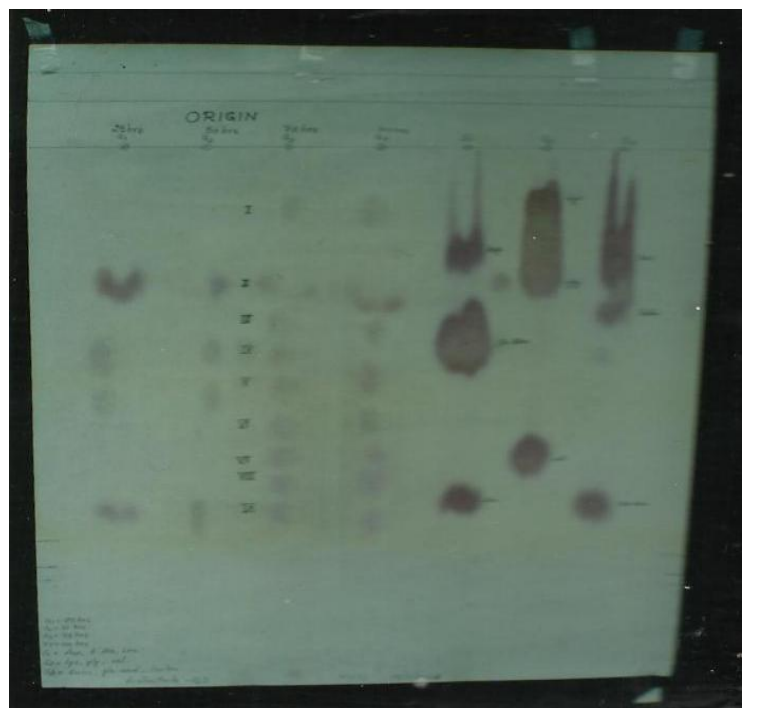

Fig.1: Chromatogam of acetonitrile-water vapour showing formation of amino acids heated up to $100 \mathrm{hrs}$. under pre biotic wetting drying conditions.

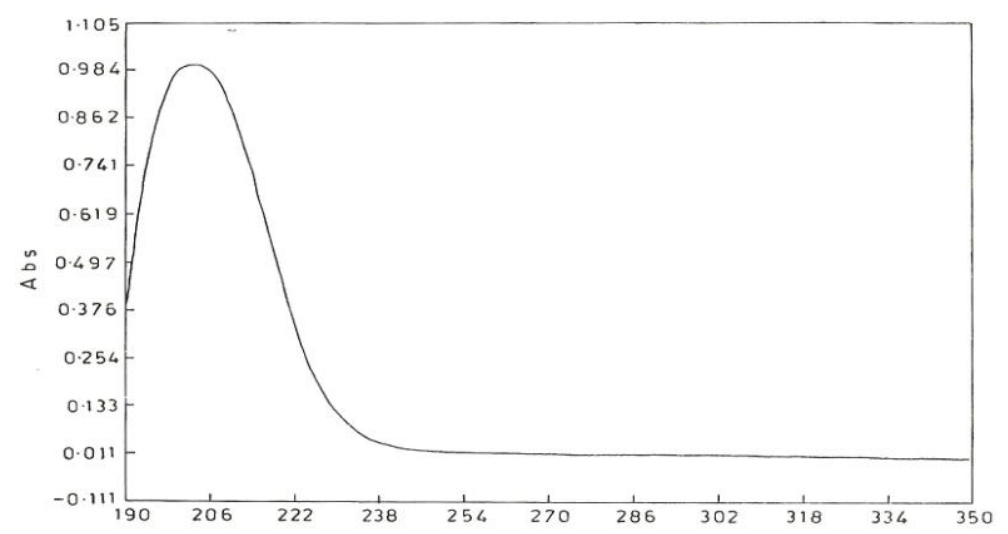

Fig. 2:UV absorption spectra of reaction concentrate of acetonitrile- water vapour heated upto $100 \mathrm{hrs}$. 


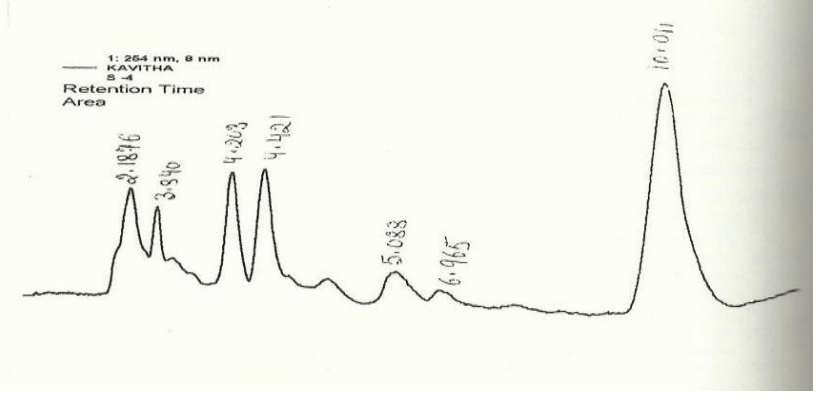

Fig. 3:HPLC of reaction concentrate of acetonitrile- water vapour heated upto $100 \mathrm{hrs}$

Table 02.

Quantity (mg/lit) and physico-chemical characteristics of products formed from reaction system of acetonitrile -water vapour heated up to $100 \mathrm{hrs}$ with montmorillonite clay with or without divalent cations under wetting-drying conditions.

\begin{tabular}{|c|c|c|c|c|c|c|c|c|c|}
\hline \multirow{2}{*}{\multicolumn{2}{|c|}{$\begin{array}{l}\text { Composition of Reaction } \\
\text { system }\end{array}$}} & \multicolumn{8}{|c|}{ No. of products formed } \\
\hline & & I & II & III & IV & $\mathrm{V}$ & VI & VII & VIII \\
\hline \multicolumn{2}{|c|}{$\mathrm{CH} 3 \mathrm{CN}-\mathrm{H}_{2} \mathrm{O}(\mathrm{V})-\mathrm{M}$} & $\mathrm{T}$ & $\mathrm{T}$ & $\begin{array}{l}0.2 \\
9\end{array}$ & $\begin{array}{l}0.3 \\
7\end{array}$ & $\mathrm{~T}$ & $\begin{array}{l}0.6 \\
3\end{array}$ & $\begin{array}{l}23 . \\
4\end{array}$ & $\mathrm{~T}$ \\
\hline \multicolumn{2}{|c|}{$\mathrm{CH} 3 \mathrm{CN}-\mathrm{H}_{2} \mathrm{O}(\mathrm{V})-\mathrm{M} . \mathrm{Cu} 2+$} & $\mathrm{T}$ & $\mathrm{T}$ & $\begin{array}{l}0.7 \\
5\end{array}$ & $\begin{array}{l}0.5 \\
5\end{array}$ & 0.46 & $\mathrm{~T}$ & $\begin{array}{l}0.7 \\
2\end{array}$ & $\mathrm{~T}$ \\
\hline \multicolumn{2}{|c|}{$\mathrm{CH} 3 \mathrm{CN}-\mathrm{H}_{2} \mathrm{O}(\mathrm{V})-\mathrm{M} . \mathrm{Ca} 2+$} & $\mathrm{T}$ & $\mathrm{T}$ & $\begin{array}{l}0.4 \\
4\end{array}$ & $\begin{array}{l}0.3 \\
3\end{array}$ & 0.41 & $\mathrm{~T}$ & $\begin{array}{l}0.6 \\
4\end{array}$ & $\mathrm{~T}$ \\
\hline \multicolumn{2}{|c|}{$\mathrm{CH} 3 \mathrm{CN}-\mathrm{H}_{2} \mathrm{O}(\mathrm{V})-\mathrm{M} \cdot \mathrm{Mg} 2+$} & $\mathrm{T}$ & $\mathrm{T}$ & $\begin{array}{l}0.3 \\
9\end{array}$ & $\begin{array}{l}0.2 \\
8\end{array}$ & 0.35 & $\mathrm{~T}$ & $\begin{array}{l}0.5 \\
6\end{array}$ & $\mathrm{~T}$ \\
\hline 1 & $\begin{array}{l}\mathrm{R}_{\mathrm{f}}(\%) \text { using } \mathrm{B}: \mathrm{A}: \mathrm{W} \\
4: 1: 1 \mathrm{~V} / \mathrm{V}\end{array}$ & 25 & 31 & 35 & 39 & 46 & 54 & 58 & 62 \\
\hline \multirow[t]{2}{*}{2} & Colour & $\mathrm{V}$ & $\mathrm{BV}$ & $\mathrm{V}$ & RV & $\mathrm{BV}$ & V & V & $\mathrm{V}$ \\
\hline & $\begin{array}{l}\text { Ninhydrin } \\
\quad \text { b. Isatin }\end{array}$ & $\mathrm{PBr}$ & $\mathrm{Db}$ & $\mathrm{BP}$ & $\mathrm{P}$ & $\mathrm{BP}$ & $\mathrm{BP}$ & $\mathrm{P}$ & $\mathrm{BP}$ \\
\hline 3 & $\begin{array}{r}\text { Solubility a. Ether } \\
\text { b. Water }\end{array}$ & $\begin{array}{l}\text { ins } \\
\mathrm{S}\end{array}$ & $\begin{array}{l}\text { ins } \\
\mathrm{S}\end{array}$ & $\begin{array}{l}\text { ins } \\
\mathrm{S}\end{array}$ & $\begin{array}{l}\text { ins } \\
\mathrm{S}\end{array}$ & $\begin{array}{l}\text { ins } \\
\mathrm{S}\end{array}$ & $\begin{array}{l}\text { ins } \\
\mathrm{S}\end{array}$ & $\begin{array}{l}\text { Ins } \\
\text { S }\end{array}$ & $\begin{array}{l}\text { ins } \\
\mathrm{S}\end{array}$ \\
\hline 4 & UV Fluorescence & WB & WB & WB & WB & WB & WB & WB & WB \\
\hline 5 & $\begin{array}{lcr}\text { Amino Acid over } \\
\text { lapped in } \\
\text { chromatography }\end{array}$ & lys & Asp & Ser & Gly & $\alpha$-ala & - & Val & leu \\
\hline 6 & Amino acid identified & lys & Asp & Ser & Gly & $\alpha$-ala & - & Val & leu \\
\hline
\end{tabular}

BAW 4:1:1 V/V n-butanol: acetic acid: water 4:1:1V/V; -,not detected; T, trace ; V, violet; B, blue; $\mathrm{P}$, pink; W, white; R, red; ins, insoluble; s, soluble; lys , lysine; asp, aspartic acid; gly, glycine; $\alpha$-ala, $\alpha$-alanine; val , valine ; leu, leucine.

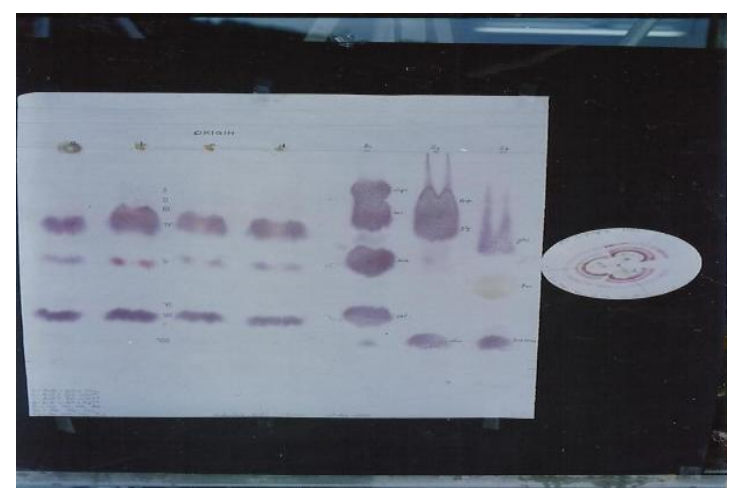


Acetonitrile: A Plausible Source Of Amino Acids On The Primitive Earth.

Fig. 4: Chromatogram showing the formation of amino acids heated upto 100 hrs. with montmorillonite clay with or without divalent cations.

[2] Lemmon, R.M.: (1970) Chemical evolution, Chem.Rev.70, 95-109

[3] Urey, H.C.:(1952) The Planets: The Origin and Development Yale Univ. Press, New Haven.

[4] Kuhn, W. : (1956) Chem. Ber. 89, 303.

[5] 5. Sanchez,R.A.,Ferris,J.P.,Orgel,L.E :(1967) .J.Mol.Evol.30,223-253

[6] 6.Bar-Nun,A.,Tauber,M.E.: (1972) .Space Life Sciences3, 254-259 .

[7] 7.Hubbard,G.E.,Hobby,G.L.,Ferris,J.P Williams,E.A.Nicoderm.D.E : (1975) J.Mol.Evol.5 223-241J.S.,Voecks,

[8] 8. Ferris,J.P.,Chen,C.T. (1975) .Nature,258,587-588.

[9] 9. Oro,J.,Kimball,A.P. (1962).Arch.Biochem.Biophys.96,293-313.

[10] 10. Oro,J.,Kimball,A.P. (1962).Arch.Biochem.Biophys.94,217-226.

[11] 11. Miller,S.L. :(1955) ,J.Am.Chem.Soc.,77:2351-61.

[12] 12.Oro,J. (1963), Natue ,197,862-67.

[13] 13 Perti,O.N.and Pathak. H.D., :(1966),Poc.Natl.Acad.Sci.(India),Section-A,Vol.XXXVI ,p.495.V V

[14] 14. Sidle,A.S.: (1967) Nature,216:408 .

[15] 15. Ponnamperuma, C. : (1972) Exobiology (North -Holland,Amsterdam and London)

[16] 16.Oro,J. :(1965) in the Origin of Prebiological systems and of their molecular Materials (ed by S.W.Fox) Academic Press, N.Y.,p, 137-71.s

[17] 17.Ferris,J.P.;Ishikawa,Y : (1988) J.Amer.Chem.Soc.110,784-785

[18] 18. Sanchez, R. A., Ferris, J.P. and : (1967) J. Molec. Biol.30, 223-253. Orgel, L.E. et al (1967)

[19] 19. . Pathak, C.K. Pant, J.N. and Pathak, H.D. : (1978) J. British interplanetary Soc. London, 33, $103-106$.

\section{Acnowledgement:}

The author is greatful to the head of chemistry and physics department for providing necessary research facility.Special thanks are due to Emeritus Prof.H.D.Pathak for his valuable suggestions from time to time. 